EGU21-15360

https://doi.org/10.5194/egusphere-egu21-15360

EGU General Assembly 2021

(c) Author(s) 2021. This work is distributed under

the Creative Commons Attribution 4.0 License.

\title{
Transport and storage of anthropogenic contaminants in the Red River Delta, Vietnam
}

\author{
Virginia Panizzo ${ }^{1}$, Lucy Roberts ${ }^{1}$, Nga Do ${ }^{2,3}$, Sarah Taylor ${ }^{1}$, Michael Watts ${ }^{4}$, Elliott Hamilton ${ }^{4}$, \\ Suzanne McGowan ${ }^{1}$, Duc Trinh ${ }^{2}$, Melanie Leng ${ }^{5,6}$, and Jorge Salgado ${ }^{1}$ \\ ${ }^{1}$ School of Geography \& Centre for Environmental Geochemistry, University of Nottingham, Nottingham, NG7 2RD, UK \\ ${ }^{2}$ Nuclear Training Center, Vietnam Atomic Energy Institute, 140 Nguyen Tuan, Thanh Xuan, Hanoi, Vietnam \\ ${ }^{3}$ Electric Power University, 235 Hoang Quoc Viet, Cau Giay, Hanoi, Vietnam \\ ${ }^{4}$ British Geological Survey, Keyworth, Nottingham, NG12 5GG, UK \\ ${ }^{5}$ National Environmental Isotope Facility, British Geological Survey, Keyworth, Nottingham, NG12 5GG, UK \\ ${ }^{6}$ Centre for Environmental Geochemistry, School of Biosciences, University of Nottingham, Sutton Bonington Campus, \\ Loughborough LE12 5RD, UK
}

Suspended particulate matter (SPM) in large rivers is the main source of material into delta river ecosystems and the world's oceans, and is the primary carrier of heavy metals. Large rivers are therefore important sources of pollutant transport through the watershed and potentially alter natural riverine biogeochemical cycling. Asian mega-deltas are some of the most densely populated and urbanizing environments in the world, with pollution, erosion, and anthropogenic catchment modifications changing sediment fluxes and pollutant transport across their catchments. The River Delta (RRD), northern Vietnam, comprises $14,300 \mathrm{~km}^{2}$, making it the fourth largest delta in Southeast Asia. The area has a large population of $>22$ million and has seen a rapid increase in industry and agriculture with waste products from domestic activities, agriculture, and industry entering the river network often unregulated and untreated. To estimate the impacts of industrialisation in the RRD delta, we measured downriver suspended sediment and pollutant flux from 21 locations over a 17 month period from March 2018 to July 2019. Previous studies suggest sediment retention in the RRD, which is supported here in 2019 with $~ 30 \%$ of sediments retained in the delta. Increased precipitation in 2018 , however, led to a $\sim 40 \%$ increase in sediment delivery between the inlet and the outlets of the delta, most likely attributed to erosion. Anthropogenic contaminant loads between the inlet and outlets suggest the retention of heavy metals within the delta irrespective of the sediment flux (e.g. a reduction by $\sim 4$ and $\sim 14 \%$ of SPM bound $\mathrm{Cr}$ between sites in 2018 and 2019). This may, in part, be due to spatial variations across the delta revealing 'hotspots' of pollution, with a progressive increase in the Cr concentration of SPM between Son Tay (a predominantly agricultural landscape) and Hanoi (a major industrialised urban area) suggesting domestic and industrial waste are major sources of heavy metal pollution. XRF data from upstream Hoa Binh reservoir sediment cores (collected 2017) will permit a comparison of background contaminant storage in the RRD catchment, to better quantify downstream impacts of anthropogenic activity as well as underpin the effects of impoundments on sediment export from 
the riverine system. Results highlight the role of deltas in 'filtering' contaminants to protect coastal areas, but the retention of high loads of pollutants also has potential consequences for the bioaccumulation of heavy metals through the food chain and could ultimately have severe consequences for aquatic and human health in these areas. 